ORIGINAL ARTICLE

AFRICAN JOURNAL OF CLINICAL AND EXPERIMENTAL MICROBIOLOGY AJCEM/201176/21202

AJCEM/201176/21202

AFR. J. CLN. EXPER. MICROBIOL 13(1): 41-45 http:/ / dx.doi.org/10.4314/ajcem/v13i1.4

\title{
DETECTION OF INFLUENZA A VIRUS IN PIGS IN LAGOS, NIGERIA
}

\author{
RUNNING TITLE: INFLUENZA A VIRUS IN NIGERIA
}

Anjorin, A. A. ${ }^{1 *}$, Omilabu, S. A. ${ }^{2}$, Salu, O. B. ${ }^{3}$, Oke, B. O. $^{4}$

\begin{abstract}
${ }^{1}$ Department of Microbiology, Lagos State University, Ojo, Lagos, Nigeria ${ }^{2}$ Department of Medical Microbiology and Parasitology, College of Medicine, University of Lagos, Idi-Araba, Lagos, Nigeria ${ }^{3}$ Department of Human virology, Microbiology Division, Nigerian Institute of Medical Research (NIMR), Yaba, Lagos ${ }^{4}$ Clinical Sciences Division, Nigerian Institute of Medical Research, Yaba, Lagos *Correspondence: Anjorin, A. A. Email: azlaboratories@yahoo.co.uk
\end{abstract}

\begin{abstract}
This study detected and subtyped strains of influenza virus from pigs in Lagos, South-western Nigeria. A total of 116 (58 nasal and 58 throat) samples from healthy pigs were analysed from two different sites in Ayedoto farm at Ojo Local Government between June and September, 2010 using reverse transcription polymerase chain reaction (RT-PCR). Influenza virus type A $31(26.7 \%)$ was detected. Subtyping was done using RT-PCR with H1, H3 and H5 primers and only subtypes H1 [5(16.1\%)] and H5 [5(16.1\%)] were detected. No positive detection was made for subtype H3. This research work is the first documented detection of influenza A virus in pigs in Lagos, Nigeria and demonstrates the need for a sustainable surveillance mechanism of swine and other influenza viruses to be able to prevent influenza epidemic in the environment.
\end{abstract}

Keywords: Subtype, Influenza A, Pig, Lagos

\section{INTRODUCTION}

The types of influenza virus found in pigs are known as swine influenzagenerally called swine flu or swineorigin influenza virus (S-OIV) $(1,2)$. Influenza virus belongs to the genus Orthomyxovirus in the family Orthomyxoviridae which consists of influenza A, B and $C$ viruses and has an envelope, single-stranded, negatively sensed RNA, eight separate segments and pleomorphic appearance with an average diameter of 120nm $(3,4)$.

Influenza A virus causes swine influenza which is an acute, highly contagious respiratory disease (5) with classical aetiological types that include influenza A subtypes H1N1, H1N2, H2N3, H3N1 and H3N2 and rarely influenza $C$ while influenza $B$ has not been reported in swine $(6,7,4)$.This is because type A group continually undergoes antigenic shift and drift unlike B and C which are relatively stable $(8,4)$. Generally, 16 haemagglutinin ( $\mathrm{H}$ or $\mathrm{HA}$ ) and 9 neuraminidase $(\mathrm{N}$ or NA) subtypes have been identified. This means pigs can also be infected with other subtypes as they play a substantially important role in the ecology of influenza A virus and can act as a "mixing vessel". When coinfections among human, avian or swine influenza viruses occur within a specific host, a new subtype can be produced by antigenic re-assortment $(9,10)$.

The virus usually spreads via aerosols produced by an infected person when coughing, sneezing or spitting or through contaminated hand to eye, nose or mouth either from fomites or direct personal contact such as hand-shake $(11,12)$.
In Nigeria, influenza viruses have caused a significant amount of morbidity in the general population but the incidence of excess mortality is unknown. Until the recent advancement in the field of molecular virology, the detection of influenza virus has always been by isolation method (13). This study therefore evaluates the detection of influenza A virus in order to establish that different strains can co-circulate among local pigs in Lagos which can cause possible intermittent infection in man.

\section{MATERIALS AND METHODS}

Study site

The study subjects were collected from pigs at two different sites in Ayedoto farm settlement, Agric, Ojo Local Government, Lagos between June and September, 2010.

Sample population, collection and preservation

A total of 58 (58 nasal and 58 throat $=116$ samples) apparently healthy land race pigs aged between 2-30 months old were the subject for this study. Nasal and throat swab samples that contained adequate numbers of ciliated and columnar epithelial cells were collected from land race pigs. Each swab was transferred into commercially available sterile cryovials containing $2 \mathrm{ml}$ aliquot of Dulbecco's modified eagle medium transport medium with antibiotic to prevent desiccation, death and bacterial growth. They were conveyed to the laboratory in coolers with dry ice packs immediately after collection. The samples were kept at $4{ }^{\circ} \mathrm{C}$ for extraction the next day $(<24 \mathrm{hrs})$ since freezing and thawing reduce the ability to recover virus. Aliquots of samples were frozen at $-70^{\circ} \mathrm{C}$.

Extraction Process 
This study extracted RNA genetic material by diatomaceous sand method using Qiagen kit (Germany). 140ul of sample was added to 560ul of lysis buffer with carrier RNA by dispensing each into sterile Eppendorf vial followed by addition of $100 \mathrm{mg}$ diatomaceous sand (Sigma-Aldrich, USA) in order to trap and bind the RNA (5). 560ul of absolute ethanol was added and mixed by pulse vortexing until homogeneous mixture was obtained. Incubation was done at room temperature for 20 minutes with vortexing at 5 minutes interval. The mixture was then spun at 13,000 rpm for 1 minute while the supernatant was decanted. Serial washings using two kinds of washing buffer (AW1 and AW2: 500ul each) were carried out before each centrifugation at 13, $000 \mathrm{rpm}$ for 1 minute and separation of supernatant. $400 \mathrm{ul}$ of acetone was later added with another vortexing and centrifugation at full speed 13,000 rpm for 1 minute. The supernatant was decanted while the pellet was drained and dried at $56{ }^{\circ} \mathrm{C}$ for 15 minutes. Elution was done with a $100 \mathrm{ul}$ of PCR water. Final vortexing and centrifugation was carried out at 13,000 rpm for 2 minutes. The supernatant was then separated and stored in RNA 1.5 ul Eppendorf tube at $-80^{\circ} \mathrm{C}$ before amplification.

\section{Master Mix Preparation and PCR Amplification}

A one step process was used for both reverse transcription and PCR amplification treatment process with Qiagen (Germany) one step kit. The master mix used for one reaction before the addition of $5 \mathrm{ul}$ of suspected influenza RNA extract for the synthesis of complementary DNA (cDNA) include: 5 ul Rnase free water, 5ul 5x RT buffer, 5ul Q-solution, 1 uldNTP-mix, $1.5 \mathrm{ul}$ each of forward and reverse primer and $1 \mathrm{ul}$ enzyme mix.

The RT-PCR mixture was then incubated at $50^{\circ} \mathrm{Cfor} 30$ minutes for reverse transcription followed by 45 cycles run in a thermo cycler (Eppendorf, Germany) PCR machine. Denaturation - 95 $\mathrm{C}$ for 15 minutes; Activation - $95 \circ \mathrm{C}$ for 30 seconds; Annealing - $55 \circ \mathrm{C}$ for 30 seconds; Elongation - 72 o Cfor 30 seconds; and Extension- $30{ }^{\circ} \mathrm{C}$ for 30 seconds $(14,15,5)$.

\section{Agarose Gel Electrophoresis Process}

Identification of amplicons was carried out by agarose gel electrophoresis method with $2 \%$ agarose gel (Peolab, Germany). 2 ul of SYBR gel stain (Invitrogen, USA) was added. The gel was later poured into a casting block with inserted comb. It was allowed to solidify for 15 minutes. The comb was gently removed whilethe gel was placed inside an electrophoresis tank containing TAE buffer 50x (Genaxxon, Germany). 1ul of 6x loading dye (Fermentas, EU) plus 5ul of amplicons were loaded per lane onto the gel. 3ul of a 100bp DNA ladder (Invitrogen, USA) was loaded along with the samples as marker. Electrophoresis was carried out in a Westburg electrophoresis machine (Biometra, Netherland) for 30 minutes by $3-4 \mathrm{~cm}$ at 130 volts. Ultra violet (UV) source safe imager trans illuminator (Invitrogen, USA) was used to illuminate and viewed the gel pictures before they were taken by Biodoc analyze 2.0(Biometra, Germany). The correct RNA amplification was indicated by correct size and a comparison with positive and negative controls of influenza A (figure 1) and subtypes $\mathrm{H} 1$ and $\mathrm{H} 5$ (figure 2).

\section{RESULTS}

A total of 116 (58 nasal, 58 throat) samples from 58 pigs were studied. Influenza A virus $31(26.7 \%)$ was detected using RT-PCR (Table 1).The 31(26.7\%) positive influenza A virus detected were typed with influenza A subtypes H1 [5(16.1\%)] and H5 [5(16.1\%)] results obtained. No positive detection was made for subtype H3 (Table 2).

TABLE 1: DISTRIBUTION OF INFLUENZA A VIRUS USING RT-PCR METHOD

\begin{tabular}{|l|l|l|}
\hline INFLUENZA TYPE & NO OF SAMPLES TESTED & NO OF POSITIVES (\%) \\
\hline A & 116 & $31(26.7 \%)$ \\
\hline
\end{tabular}

TABLE 2: DISTRIBUTION OF SUBTYPES OF INFLUENZA A VIRUS USING H1, H3 AND H5 PRIMERS

\begin{tabular}{|l|l|l|}
\hline & NO OF SAMPLES TESTED & NO OF POSITIVES (\%) \\
\hline H1 & 31 & $5(\mathbf{1 6 . 1} \%)$ \\
\hline H3 & 31 & - \\
\hline H5 & 31 & $\mathbf{5 ( 1 6 . 1 \% )}$ \\
\hline
\end{tabular}


A

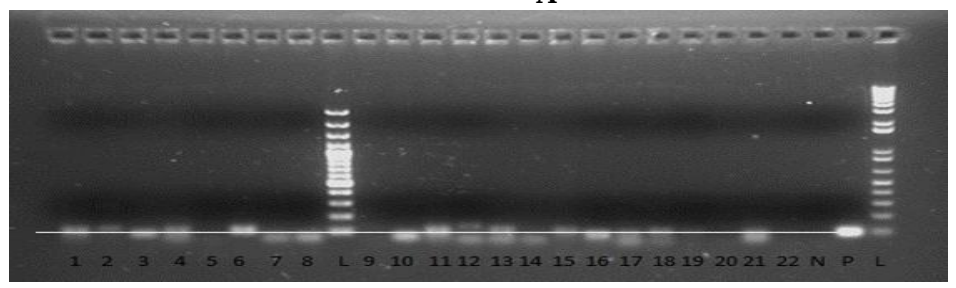

B

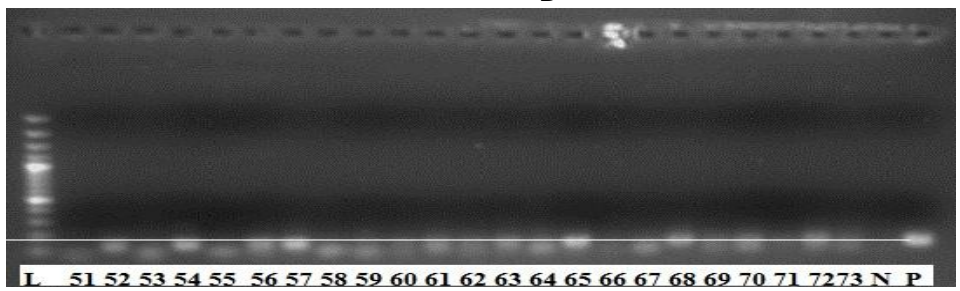

C

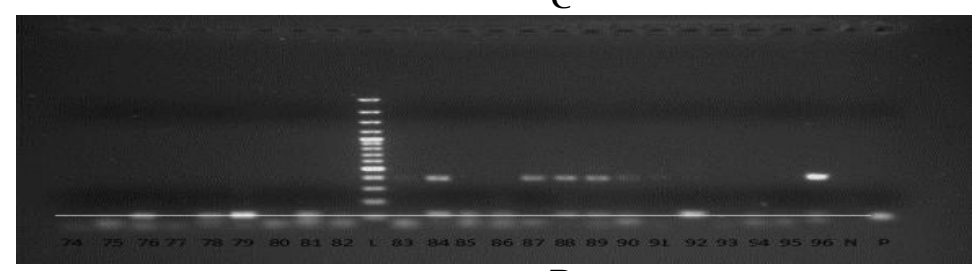

D

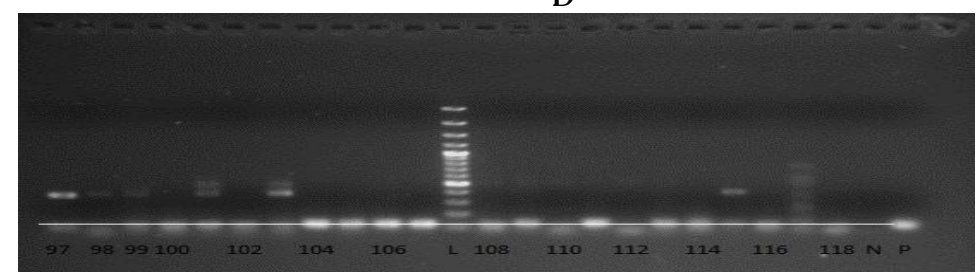

Figure 1:Amplicons of Influenza A virus separated by Agarose Gel Electrophoresis (2\%) for 30 minutes by $3-4 \mathrm{~cm}$ at 130 volts:Panel A has seven total no of positives as shown on lane 1, 4, 11, 12, 13, 17 and 18 when compared with the positive control (P) on last lane as ruled by the straight line passing through the center; Panel B has fivetotal no of positives $(57,65,68,70$ and 72$)$; Panel C. No of positives $=6(76,78,79,81,85$ and 86); Panel DNo of positives $=13(100,101,102,104,105,106,107,108,109,111,113$, 114 and 116). 
A

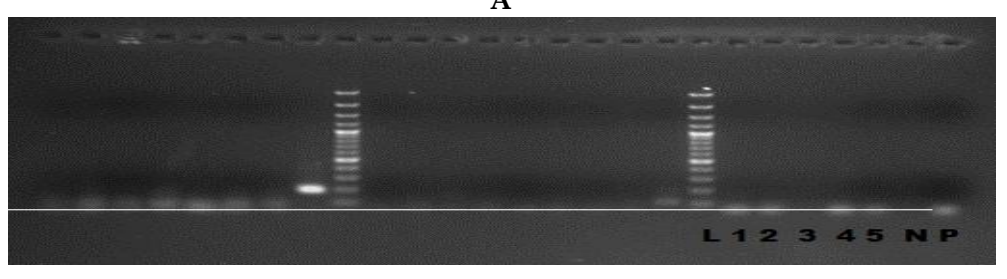

B

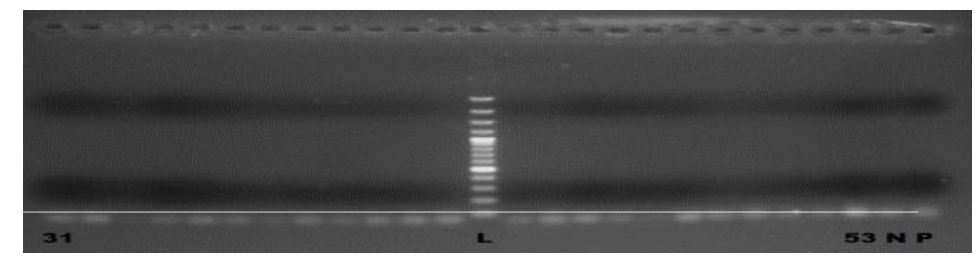

C

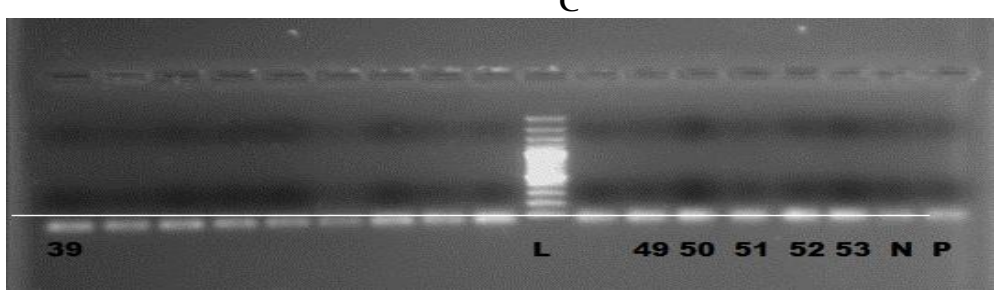

Figure 2:Amplicons ofHaemagg1utinin $(\mathrm{H}) 1$ and Haemagglutinin $(\mathrm{H}) 5$ protein genes of subtypes of Influenza A virus separated by Agarose Gel Electrophoresis (2\%) for 30 minutes by 3-4cm at 130 volts:PanelA.Subtype H1; No of positives = 4 (1, 2, 4 and 5); PanelB. Continuation of SubtypeH1; No of positives = 1 (53);Panel C.SubtypeH5; No of positives = 5 (49, 50, 51, 52 and 53). Negative (N) and Positive (P) controls are as shown on second to the last and last lane respectively. 100 base pair Ladder (L) was used as the marker as shown on each gel panel.

\section{DISCUSSION}

Influenza virus is notoriously known for its unique ability to cause recurrent influenza epidemics and global pandemics during which acute febrile respiratory illness occurs explosively. There are two qualities of influenza virus that account for much of its spread. First is the ability to emerge and circulate in avian or porcine reservoirs by either genetic reassortment or direct transmission and subsequently spread to human at regular intervals. Second, is the fast and unpredictable antigenic change ofimportant immune target once the virus is established in human (16).

The high number of positive results to influenza A virus $31(26.7 \%)$ detected in this study is characterized by its continuous antigenic drift and shift, making it more genetically diverse with high prevalence in the subject $(8,4)$. This is further supported by the work of (17) which showed that influenza A virus mutates at a rate 2-3 times faster than type $B$ which is relatively stable.

Only sub types H1 [5(16.1\%)] and H5 [5(16.1\%)]detected in this study disagree with the work of (1) and (5) that detected subtype H3 in pigs. (18) and (19) also detected and worked on both H1 and H3 Thailand and European subtypes in pigs respectively. No positive detection of $\mathrm{H} 3$ in this study may be due to $\mathrm{H} 3$ primer mismatch to local strains of influenza A in Nigeriasince foreign primer (Qiagen, Germany) were used which produced unclassified bands.

The detection of H5 agrees with the work of several authors since H5 subtypes are commonly found in birds (20). Another reason is that birds are being reared side by side with the pigs at the site of this study. Subtyping in this study however did not include the use of neuraminidase $(\mathrm{N})$ primers due to cost and in availability in Nigeria.

The ability of RT-PCR to detect influenza virus types agree with the work of (21) that RT-PCR is capable of detecting the virus even when the viral genomes are present in low level and is generally more sensitive in

the detection of influenza virus than any other method including serology and culture (22). 


\section{REFERENCES}

1. Adeola OA, Adeniji JA, Olusaga BO. Isolation of influenza A viruses from pigs in Ibadan, NigeriaVet. Ital. 2009; 45(3): 383-90

2. Faix DJ, Sherman SS, Waterman SH. Rapid-test sensitivity for novel swine origin influenza A (H1N1) virus in humansN Engl J Med. 2009; 361: 7

3. Gurtler, L. Virology of human influenza. In:Kamps, B. S., Hoffmann, C., Preiser, W. (eds) Influenza report 2006. Flying Publisher, Wuppertel 2006:87-91

4. Fowotade A, Agbede O, Nwabuisi C, Fadeyi A. A review of swine influenza: an emerging pandemicNigHospPract. 2009; 4: 3-4

5. Sreta D, Kedkovid R, Tuamsang S, Kitikoom P, Thanawongnuwech R. Pathogenesis of swine influenza virus (Thai isolates) in weanling pigs: an experimental trial Virol. 2009; 6: 34

6. Shin JY, Song MS, Lee EH. Isolation and characterization of novel H3N1 swine influenza viruses from pigs with respiratory diseases in Korea J of ClinMicrobiol. 2006; 44(11): 3923-7

7. Vincent $\mathrm{AL}$, Lager KM, Ma W. Evaluation of haemmaglutinin subtype 1 swine influenza viruses from the United StatesVet Microbiol. 2006; 12-22

8. Brooks, G. F., Carol, K. C., Butel, J. S., Morse, S. A. Orthomyxoviruses (Influenza viruses). In: Jawetz, Melnick,Adelberg's Medical Microbiology. McGraw Hill, New York 2007

9. Easterday, B. C. Animal influenza. In:Kilbourne, E. D.(ed) The influenza viruses and influenza. Academic Press, Orlando 1975: 449-481

10. Webster R, Ox N, Stohl K. WHO manual on animal influenza diagnosis and surveillance. World Health Organization 2002: 15-67

11. Hall CB. The spread of influenza and other respiratory viruses: complexities and conjuctures. Clin Infect Dis. 2007; 45(3): 353-9
12. Weber TP, Stalianakis, NI. Inactivation of influenza viruses in the environment and modes of transmission: a critical review. J of Infect. 2008; 57(5): 361-73

13. Vanzyl, G. Laboratory findings. In:Kamps, B. S., Hoffman, C., Preiser, W. (eds) Influenza report 2006. Flying Publisher, Wuppertal 2006: 150-159

14. Boom R, Sol, CJ. Rapid and simple method for purification of nucleic acids. J of ClinMicrobiol. 2006; 28: 495-503

15. Cox, N. J., Neumann, G., Donis, R. O.,Kawaoka, Y. Orthomyxoviruses: Influenza. In: Microbiology and Microbial Infections: Virology. 10thedn. Edward Arnold Publisher, Washington 2005:634-680

16. Behrens, G and Stoll, M. Pathogenesis and Immunology. In:Kamps, BS, Hoffman C, Preiser W.(eds) Influenza report 2006. Flying Publisher, Wuppertal 2006

17. Nobusawa F, Sato K. Comparison of the mutation rates of human influenza A and B. J Virol.2006; 80 (7): 3675-8

18. Damrongwatanapokin S, Pinychon W, Parchariyanon S,Damrongwatanapokin T. Serological study and isolation of influenza A virus infection of pigs in Thailand. Proceedings of the 19th IPVS Congress, Denmark 2006

19. Van Reeth K, Gregory V, Hay A, Pansaert M. Protection against European H1N2 swine influenza virus in pigs previously infected with H1N1 and/ or H3N2 subtypes. Vaccine. 2003; 21: 1375-1381

20. Olofson S, Kumlin U, Dimock K, Arnberg N. Avian influenza and sialic acid receptors: More than meets the eye? Lancet Infect Dis. 2005; 5: 184-8

21. Landolt, GA, Karasin, AL, Phillips L, Olsen, CW. Comparison of the pathogenesis of two genetically different H3N2 influenza A viruses in pigs. J of ClinMicrobiol. 2003; 941:1936-1941

22. Zambon M, Hays J, Webster A, Newman R, Keene O. Diagnosis of influenza in the community: relationship of clinical diagnosis to confirmed virological, serological or molecular detection of influenza. Arch. InternMed. 2001; 161: 2116-22 
